\title{
Ultrasonic Blood Flow Measurement in Haemodialysis
}

\author{
D. SAMPSON, ${ }^{*}$ B.SC., F.R.C.S., F.R.C.S.ED.; M. PAPADIMITRIOU,† M.D.; A. E. KULATILAKE, † F.R.C.s., F.R.C.s.ED.
}

British Medical fournal, 1970, 1, 340-341

S ummary : A 5-megacycle Doppler flow meter, calibrated in-vitro, was found to give a linear response to blood flow in the ranges commonly encountered in haemodialysis. With this, blood flow through artificial kidneys could be measured simply and with a clinically acceptable error. The method is safe, as blood lines do not have to be punctured or disconnected and hence there is no risk of introducing infection. Besides its value as a research tool the flow meter is useful in evaluating new artificial kidneys. Suitably modified it could form the basis of an arterial flow alarm system.

\section{Introduction}

Several methods are available for measuring the blood flow in artificial kidneys. The simplest is the bubble method in which a small bubble is introduced into one of the blood lines and its progress between two points is timed with a stop-watch. If the length of the tube traversed is known its volume can be calculated or measured and a reasonably accurate estimate of blood flow obtained (Jameson, 1966). This method suffers from the disadvantage that blood lines have to be punctured and there is a risk of introducing infection, and also of air embolism.

Electromagnetic flow meters have been used (Brennand and Bunker, 1960), but the flow head had to be inserted into the blood circuit with consequent risk of introducing infection. Sterilization of these flow heads is difficult and time-consuming; they are also subject to zero drift and are expensive for routine use. Thermistors, which have been used for intravascular blood flow measurements, suffer from the same disadvantages when used for blood flow measurement in haemodialysis.

The ultrasonic principle of blood flow measurement makes use of the Doppler effect. A 5-megacycle beam of sound is directed through the blood stream and a small fraction of the beam is backscattered from particles in the blood to the receiver crystal. The resulting frequency shift is proportional to the blood velocity, and in a vessel of given diameter this frequency shift is proportional to total blood flow (Rushmer et al., 1966; Miller, 1968).

The method is not as accurate as other techniques of blood flow measurement but has the great advantage that the ultrasonic probe can be placed on blood lines without disconnecting or puncturing them; it is also perfectly safe as there is no possibility of introducing infection, and at the energies used, which are in the order of milliwatts, there is no damage to red cells. The equipment does not suffer from zero drift and can be used by non-technical personnel.

The aim of the present study was to investigate the use of an ultrasonic Doppler flow meter for routine blood flow measurements in haemodialysis.

\footnotetext{
* Registrar and Tutor in Surgery.

+ N.A.T.O. Scholar and Honorary Registrar.

¥ Senior Registrar and Senior Tutor in Surgery.

Urology Unit, Department of Surgery, Hammersmith Hospital and Royal Postgraduate Medical School, London W.12.
}

\section{Materials and Methods}

A 5-megacycle ultrasonic Doppler flow meter was used for the study. An in-vitro system was set up for calibration of the equipment, which consisted of a blood reservoir, a rotary blood pump, and a rigid frame in which to mount the probe so that the angle of the probe to the blood line could be varied. The output of the flow meter was recorded on a Beckman pen recorder, and when measuring pulsatile flow the peak deflections of the pen recorder were plotted against the actual blood flow as measured by a timed collection of blood in a measuring cylinder. The output for varying diameter tubes was plotted, one of the tubes being the arterial line of a Kiil dialyser. For a given diameter tube several plots were made, varying the angle of the probe to the blood line. The experiments were repeated, the blood being diluted with an equal volume of saline in order to determine the effect of variation in packed cell volume on the output signal.

With the in-vitro system the bubble method was also assessed against direct blood flow measurement as it was to be the standard against which the ultrasonic method was compared in Kiil dialysers.

The probe was used to measure blood flow in haemodialysis by mounting it in a frame so that the angle of the probe was at $30^{\circ}$ to the arterial line of the Kiil dialyser. The probe head was held in light contact with the tubing, and the small space between the two was filled with an aqueous jelly ensuring adequate transmission of the beam through the tubing. At the same time as the recording was taken, a bubble of air was introduced into the arterial line and its progress between two marked points timed with a stop-watch. At the end of the dialysis the arterial line was saved and the volume of tubing between the two marked points was measured directly by filling it with water and emptying this into a measuring cylinder. Thus the actual blood flow rates could be calculated, and these were plotted against an average of the peak signals given by the probe.

\section{Results}

Probe output plotted against actual blood flow in-vitro for the Kiil arterial line is shown in Fig. 1. A linear response is obtained between 70 and $250 \mathrm{ml}$./min., which is well within the ranges commonly encountered in haemodialysis with a Scribner shunt and a Kiil dialyser. The output of the probe varied with the angle of the probe to the vessel when plots were made for varying angles from $10^{\circ}$ to $30^{\circ}$. The bubble method was found to be accurate when bubble transit time was plotted against actual blood flow in-vitro.

When the in-vitro ultrasonic blood flow measurements were repeated with blood diluted with an equal volume of saline, thus reducing the packed cell volume by half, the signal was found to be reduced by about $10 \%$ but the same linearity of response was maintained.

The plot of the probe output and blood flow as measured by the bubble method in patients who were being dialysed on Kiil dialysers is shown in Fig. 2. A linear relationship is seen, but the correlation coefficient has dropped from 0.99 to 0.89 when compared with the in-vitro experiment. 


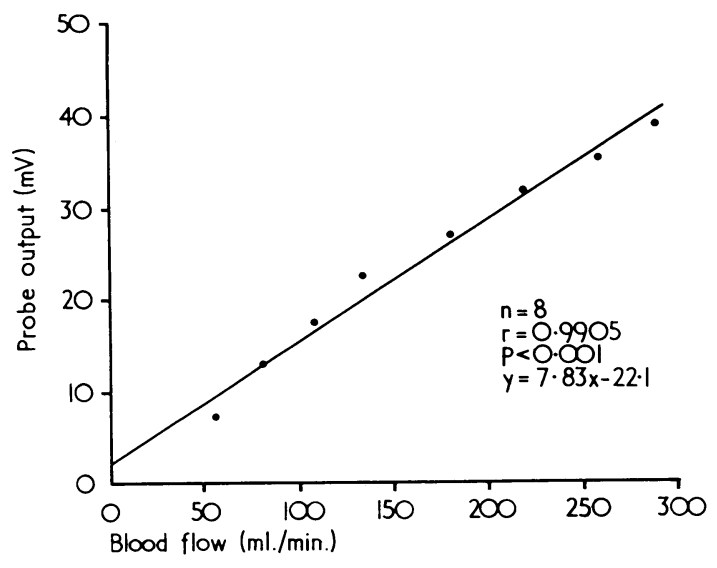

Fig. 1.-In-vitro calibration of 5-megacycle ultrasonic Doppler flow meter with a Kiil arterial line. Probe $30^{\circ}$
to line.

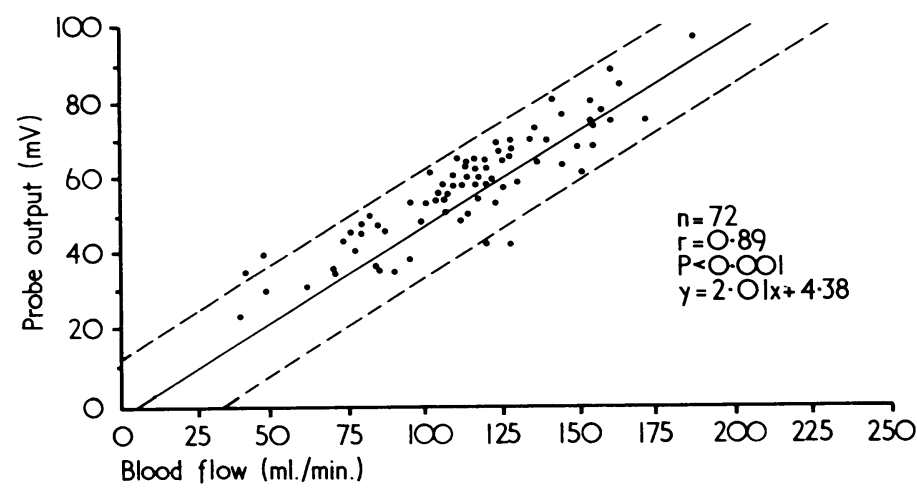

FIG. 2.-Calibration of 5-megacycle ultrasonic Doppler flow meter during haemodialysis.

\section{Discussion}

The dialysance of urea and creatinine are related to blood flow in an almost linear fashion (Kulatilake et al., 1969) and, for an effective dialysis, blood flow through most artificial kidneys must be in the order of $150-200 \mathrm{ml} . / \mathrm{min}$. Consequently, a simple method of measuring blood flow in haemodialysis is required. The objections to the bubble method and the electromagnetic flow meter have been mentioned.

There have been few attempts to use ultrasound quantitatively in clinical practice, most applications being qualitative, largely in the field of peripheral vascular disease
(Strandness et al., 1967) and obstetrics (Bellamy and Stickland, 1967). The use of an ultrasonic flow meter to measure blood flow in Scribner shunts has been described (Walls and Kopp, 1968), but the limitations of the method were not discussed. The results show that the ultrasonic flow meter is a very convenient and reasonably accurate method of measuring blood flow for in-vitro systems, and it is felt that it is of considerable value as a research tool. We have used the instrument for measuring blood flow in isolated renal perfusion experiments with some success.

When measuring blood flow in an in-vivo system such as that encountered in haemodialysis, there is some sacrifice of accuracy for convenience. This is because the technique involves the averaging out of peak flows and does not take into account any variation of wave form that may occur from one patient to another. In clinical dialysis, however, great accuracy is not required and the method has been of value in assessing the performance of new disposable kidneys (Kulatilake et al., 1969). It appears from our results that the common clinical variations in the packed cell volume have negligible effect on the accuracy of the method.

With the increasing use of Cimino-Brescia subcutaneous arteriovenous fistulae in chronic haemodialysis, there is a need for an alarm system monitoring arterial flow. Damage to the fistulae can be caused by the speed of the blood pump being too great for the arterial output of the fistula. The present alarm systems, which are either electromagnetic flow meters or pressure recorders, have not proved satisfactory. We have had some encouraging experience with an alarm system based on an ultrasonic flow meter.

We have monitored the flow in Scribner shunts and found that this does not correlate well with the flow when the patient is connected to a Kiil dialyser. This is the result of individual variations in resistance to flow in Kiil dialysers, and thus flow measurements in Scribner shunts are unable to predict the adequacy of blood flow on dialysis.

The Doptone ultrasonic flow meter was found to be reliable and stable. During the evening, however, radio interference occasionally made accurate recording difficult. The approximate cost of the instrument used was $£ 200$.

We would like to thank Professor R. Shackman for permission to study his patients. We would also like to thank Messrs. Smith Kline Instrument Company, Welwyn Garden City, Herts., for the loan of the Doppler flow meter and the ultrasonic Doplarm.

\section{REFERENCES}

Bellamy, R. J., and Stickland, R. G. (1967). Biomedical Engineering, 2, 262

Brennand, R., and Bunker, N. V. (1960). Lancet, 1, 578.

Jameson, R. M. (1968). British Medical fournal, 2, 176

Kulatilake, A. E., Sampson, D., Papadimitriou, M., Vickers, J., and Shackman, R. (1969). Proceedings of 6th European Dialysis and Transplant Association Conference, 1969.

Miller, J. T. (1968). Principles of Instrumentation, p. 36. United Trade Press Limited.

Rushmer, R. F., Baker, D. W., and Stegall, H. F. (1966). Fournal of Applied Physiology, 21, 554

Strandness, D. E., Sehultz, R. D., Sumner, D. S., and Rushmer, R. F (1967). American fournal of Surgery, 113, 311 .

Walls, J., and Kopp, H. (1968). British Medical fournal, 2, 806. 